\title{
Rising Accents in Castilian Spanish: \\ A Revision of Sp_ToBI
}

\author{
TIMOTHY L. FACE AND PILAR PRIETO
}

\begin{abstract}
This paper employs Castilian Spanish data to examine the issue of rising pitch accents and their phonological analysis. The preliminary $S p \_T o B I$ annotation conventions are shown to be inadequate for representing the Castilian Spanish data, and therefore a revision is proposed. Through an examination of data on Castilian Spanish rising accents in a variety of sentence types, two primary contributions are made in this paper. First, new empirical data on the inventory of rising pitch accents in Castilian Spanish is provided, showing that there is a three-way contrast that must be accounted for. Secondly, an analysis of rising accents is proposed that is based on the secondary association of pitch accent tones that not only is able to account for the three-way contrast in rising accents, but which offers a more straightforward manner of assigning starredness in bitonal pitch accents.
\end{abstract}

\section{Introduction}

In October 1999, a workshop was held at The Ohio State University for the purpose of developing a transcription system for Spanish intonation within the Tones and Break Indices (ToBI) framework (Jun, 2005). As a result of this workshop, Beckman, Díaz-Campos, McGory \& Morgan (2002) published a preliminary proposal for Spanish ToBI (Sp_ToBI) that was intended to be "a consensus transcription system" (p. 10) as the authors were representing a group of scholars - both workshop participants and others - from a variety of backgrounds, all interested in developing a consensus Sp_ToBI transcription system. $^{1}$ As Beckman et al. (2002) recognized, before an Sp_ToBI system

\footnotetext{
${ }^{1}$ It should be noted that Ortiz Lira (1999), prior to the Sp_ToBI workshop, had attempted to apply the ToBI system of English (Beckman \& Ayers 1994) to the Spanish of Chile. The Sp_ToBI system proposed by Beckman et al. (2002), however, has been more widely recognized, likely due at least in part to its broader
} 
could be built, it was important to achieve an analysis of Spanish intonation, with which there was broad agreement, within the Autosegmental-Metrical (AM) model of intonational phonology (Pierrehumbert, 1980; Beckman \& Pierrehumbert, 1986; Pierrehumbert \& Beckman, 1988; Ladd, 1996). Therefore, while they mentioned other aspects of their preliminary Sp_ToBI system, Beckman et al. (2002) focused the majority of their article on a phonological analysis of Spanish intonation within the AM model. While the preliminary Sp_ToBI transcription system proposed by Beckman et al. (2002) was a very important first step, there has been relatively little continuity of the Sp_ToBI development group after that first meeting, in spite of the $2^{\text {nd }}$ Spanish ToBI Workshop being held in Barcelona, Spain in $2005 .{ }^{2}$ Furthermore, the Sp_ToBI system proposed by Beckman et al. (2002) was intended to be a preliminary set of tagging conventions, as noted explicitly at various points in their paper. ${ }^{3}$

Although the Sp_ToBI system as proposed in Beckman et al. (2002) is preliminary, researchers often take it as a firm proposal with strong consensus (e.g. Kimura, 2006; Sahyang, Andruski, Casielles, Nathan \& Work, 2006; Velázquez, 2006). This is particularly problematic since in several ways this preliminary system seems to be quite "out of touch" with current work on Spanish intonation, and in our view is in considerable need of revision. The most relevant example for the present paper is the inventory of pitch accents proposed (i.e. $\mathrm{H}^{*}, \mathrm{~L}^{*}, \mathrm{~L}+\mathrm{H}^{*}, \mathrm{~L}^{*}+\mathrm{H}$, and $\mathrm{H}+\mathrm{L}^{*}$ ). While $\mathrm{H}^{*}$ was a common analysis of rising accents in Spanish, many analyses no longer use this accent. Also, other accents have been motivated in other studies but are not included in the preliminary $\mathrm{Sp}_{-}$ToBI system, such as $\mathrm{H}^{*}+\mathrm{L}$ in the work of Ortiz Lira (1999) and Sosa (1999).

In this paper we will focus on the issue of rising accents and their phonological analysis, which is an area where the preliminary Sp_ToBI proposal encounters at least two basic problems: 1) the ambiguous manner by which starredness is assigned to one tone of bitonal pitch accents, and 2) the

desire to provide a pan-Spanish ToBI system. For more details, see the Sp_ToBI webpage at http://www.ling.ohio-state.edu/ tobi/sp-tobi/spanish.html.

2 The $2^{\text {nd }}$ Spanish ToBI Workshop, organized by José Ignacio Hualde, was held in Barcelona in conjunction with the Phonetics and Phonology in Iberia (PaPI) conference in June 2005. This workshop differed from the first workshop in that it consisted of a number of individual presentations, some of which focused on the difficulties of the Sp_ToBI model for the labeling of different databases. Many presentations from the PaPI conference and from the $2^{\text {nd }}$ Spanish ToBI Workshop are available online at http://seneca.uab.es/papi.

${ }^{3}$ Beckman et al. (2002:32), for example, state that "it is also clear that much work remains to be done before $\mathrm{Sp}_{-}$ToBI can become the standard communal resource that some of the older Sp_ToBI systems already are. We have raised far more questions than can be answered now or in the near future...We summarize by listing the preliminary set of conventions." It is also worth noting that Spanish is listed under the heading "Partially-developed systems have been described for:" on the ToBI website: http://www.ling.ohio-state.edu/ tobi/ 
assumption that there is only a two-way contrast in rising accents. ${ }^{4}$ While these issues are not unique to Spanish - indeed the issue of assigning starredness has received considerable attention in the field of intonational phonology in recent years - our Castilian Spanish data present challenges to both the assumption that there is only a two-way contrast in rising accents and to the manner in which starredness is commonly assigned to bitonal accents. Through an examination of our data on rising accents in Castilian Spanish, the variety spoken in the central region of Spain, we will make two primary contributions in this paper. First, we will provide new empirical data on the inventory of rising pitch accents in Castilian Spanish, showing that there is a three-way contrast that must be accounted for. Secondly, we will propose an analysis based on the secondary association of pitch accent tones that not only is able to account for the three-way contrast in rising accents, but which offers a more straightforward manner of assigning starredness in bitonal pitch accents.

The remainder of this paper is organized as follows. In Section 2 we provide a discussion of the various analyses of rising pitch accents that have been proposed for Spanish and of the problems that have been pointed out for the standard analysis of these accents. In Section 3 we present empirical data and show that there is a three-way contrast in rising accents in Castilian Spanish. Section 4 presents our proposal for accounting for the three-way contrast in rising accents by incorporating secondary associations of pitch accent tones into the AM model. We also argue that this proposal provides a more straightforward manner of assigning starredness in bitonal pitch accents. Finally, in Section 5 we conclude by pointing out similar three-way contrasts in other Romance languages and discuss the importance of incorporating such contrasts into the phonological representation of intonation. We also argue that by doing so for Castilian Spanish we not only offer a way for the AM model to deal with previously challenging data, but also take a step towards making the Sp_ToBI system more transparent.

\section{Spanish rising accents within the AM model}

\subsection{The original Sp_ToBI analysis}

For several years, the 'standard' view in transcribing Spanish rising pitch accents has been that of Sosa $(1995,1999)$ and later Face $(2001 c, 2002 a$, 2002b, 2003). Sosa, for the Spanish of Caracas, and Face, for Castilian Spanish, have shown that there are two distinct types of F0 rises. In these

\footnotetext{
${ }^{4}$ The fact that $\mathrm{Sp} \_$ToBI includes $\mathrm{L}+\mathrm{H}^{*}, \mathrm{~L}^{*}+\mathrm{H}$, and $\mathrm{H}^{*}$ should not lead readers to interpret this as representing a three-way contrast. As we will see in Section 2.1, the label $\mathrm{H}^{*}$ is used within Sp_ToBI only as a place holder when a syllable sounds accented but the labeler cannot yet decide which of the two rising accent labels (i.e. $\mathrm{L}+\mathrm{H}^{*}$ and $\left.\mathrm{L}+\mathrm{H}^{*}\right)$ is the best analysis.
} 
varieties (and in several others), one type of rising pitch accent is characterized by an F0 valley at or near the onset of the stressed syllable and an F0 peak occurring in a post-tonic syllable. The other rising pitch accent is also characterized by an F0 valley at or near the onset of the stressed syllable, but differs from the other accent in that the F0 peak is reached within the temporal boundaries of the stressed syllable. The Sp_ToBI proposal put forth by Beckman et al. (2002) follows these authors and chooses two different representations for these two types of rising pitch accents. In order to understand the analyses assigned, we look at the labels assigned to these pitch accents by Beckman et al. (2002) and the definitions of each that they provide.

The Sp_ToBI proposal by Beckman et al. (2002) includes two firm labels for rising pitch accents: $\mathrm{L}^{*}+\mathrm{H}$ and $\mathrm{L}+\mathrm{H}^{*}$. The $\mathrm{L}^{*}+\mathrm{H}$ label is used for the accent described above as having a peak on the post-tonic syllable in Caracas and Castilian Spanish. The $\mathrm{L}+\mathrm{H}^{*}$ label is used for the accent described as having a peak on the tonic syllable. The definitions given for each label by Beckman et al. (2002:33) are as follows:

$\mathrm{L}^{*}+\mathrm{H}$ late rising accent, with peak after the stressed syllable and valley toward the beginning...or toward the middle of the stressed syllable.

$\mathrm{L}+\mathrm{H}^{*}$ early rising accent, with peak during the stressed syllable...or just after the end of the stressed syllable if the syllable is intrinsically short.

It should be noted that these definitions refer to $\mathrm{L}^{*}+\mathrm{H}$ as a 'late rising accent' and to $\mathrm{L}+\mathrm{H}^{*}$ as an 'early rising accent'. These terms are perhaps a bit misleading, and in fact there is ambiguity as to what these accents refer to. On the one hand, in some dialects what really distinguishes these accents is not when the rise occurs, but rather where the peak is realized. Therefore $\mathrm{L}^{*}+\mathrm{H}$ might be better characterized as having a 'late peak' and $\mathrm{L}+\mathrm{H}^{*}$ as having an 'early peak'. While the definition of $\mathrm{L}+\mathrm{H}^{*}$ does not mention the valley location, it typically occurs near the onset of the stressed syllable, much like in the case of the $\mathrm{L}^{*}+\mathrm{H}$ accent. These $\mathrm{L}^{*}+\mathrm{H}$ and $\mathrm{L}+\mathrm{H}^{*}$ labels are the same as those proposed by Sosa $(1995,1999)$ and Face $(2001 c, 2002 a, 2002 b, 2003)$ for these accents. On the other hand, there is ambiguity in the definition of the $\mathrm{L}^{*}+\mathrm{H}$ accent as the definition indicates that the valley occurs "toward the beginning...or toward the middle of the stressed syllable." Where the valley occurs depends on the variety of Spanish, according to Beckman et al. (2002), and one of the examples on the Sp_ToBI website shows a case with a laterising accent, where the rise begins late in the stressed syllable. ${ }^{5}$ The Sp_ToBI proposal, then, employs the $\mathrm{L}^{*}+\mathrm{H}$ label to refer to any rising accent with a late peak, but assumes that the implementation of the valley differs across

\footnotetext{
${ }^{5}$ The example can be found in the Sp_ToBI webpage: http://www.ling.ohio-state.edu/ tobi/sp-tobi/spanish.html.
} 
varieties of Spanish. Crucial to this analysis is the claim that an early rising and late rising accent, both with peaks in the post-tonic syllable, do not occur contrastively in the same variety of Spanish. As we will show in Section 2.3 and in Section 3, this is not the case. Schematic representations of the intonation patterns represented by these $\mathrm{Sp}$ _ToBI labels, including the multiple rising patterns represented by the $\mathrm{L}^{*}+\mathrm{H}$ label, are seen in Figure 1.

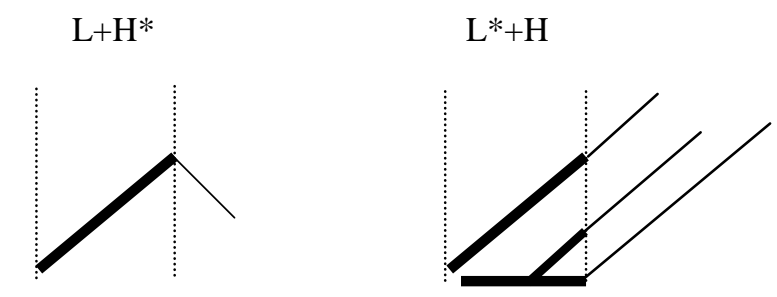

Figure 1. Schematic representations of the F0 patterns represented by the $\mathrm{L}+\mathrm{H}^{*}$ and $\mathrm{L}^{*}+\mathrm{H}$ labels within the $\mathrm{Sp} \_$ToBI system.

It is important to note here that $\mathrm{L}^{*}+\mathrm{H}$ and $\mathrm{L}+\mathrm{H}^{*}$ are distinct phonological units, and one would expect them to be applied to contrasting pitch accents. In both Caracas and Castilian Spanish, as well as other varieties, the $\mathrm{L}^{*}+\mathrm{H}$ label is used for the prenuclear pitch accent in declaratives, while the $\mathrm{L}+\mathrm{H}^{*}$ label is used for the nuclear accent. ${ }^{6}$ As these two accents are in complimentary distribution, one might question whether they merit distinct phonological representations. While we will show in Section 3 that both of these accents occur in prenuclear position in Castilian Spanish with distinct meaning, and thus do indeed contrast, much of the motivation for these pitch accents has come from their use in prenuclear and nuclear positions. Beckman et al. (2002:16-17) discuss the debate in the literature on whether prenuclear and nuclear accents merit distinct phonological analyses, although they opt for maintaining a phonological distinction between prenuclear $\mathrm{L}^{*}+\mathrm{H}$ and nuclear $\mathrm{L}+\mathrm{H}^{*}$ accents. While they discuss the evidence that leads them to make this decision, they also comment on the goal of Sp_ToBI to provide a pan-Spanish transcription system: "On the principle that a pan-Spanish ToBI should overspecify rather than under-specify, however, the Sp_ToBI group recommended differentiating the tags for early and late peaks even for those... varieties where the difference may be allophonic" (p. 17).

Beckman et al. (2002:33) also propose two tentative labels to be used "when a syllable sounds accented, but is difficult to identify as one of the

\footnotetext{
${ }^{6}$ The term nuclear was originally used to refer to the most prominent accent within a phrase. However, likely due to the nuclear accent generally being the final accent of a phrase in several languages, the term has also been used to refer to the final accent of a phrase, regardless of its degree of prominence. Since the latter use has become typical in work on Spanish intonation, it is the use that we adopt here.
} 
above [accents]"; given this difficulty, the tentative labels are to be used "as a place holder for later re-analysis after the inventory of tunes in this dialect is better understood". One of the place holders is the label $\mathrm{H}^{*}$, which has at times been used as an analysis of rising accents in Spanish (see Section 2.2). The definition of this label provided by Beckman et al. (2002:33) is as follows:

$\mathrm{H}^{*}$ a clear small peak during the accented syllable, at about the same level as a clear prior $\mathrm{L}^{*}+\mathrm{H}$, when the lack of a minimum cannot be attributed to upstep and undershoot.

Therefore, although $\mathrm{H}^{*}$ is a label that could be (and has been; see below) used in the analysis of rising accents, within Beckman et al.'s (2002) Sp_ToBI proposal it is not a firm analysis, but rather a place holder for re-analysis once scholars achieve a better understanding of the intonational system under investigation. In this way Sp_ToBI follows English ToBI, which uses $\mathrm{H}^{*}$ as a default label when there is uncertainty as to the appropriate accent label.

\subsection{Other AM analyses of Sp_ToBI's $L^{*}+H$ and $L+H^{*}$ accents}

Work by Prieto and her colleagues in the 1990s (Prieto, van Santen \& Hirschberg, 1995; Prieto, Shih \& Nibert, 1996; Prieto, 1998) analyzed rising accents in Mexican Spanish, conducting detailed experiments to understand their behavior. The phonological analysis of the accents provided was $\mathrm{H}^{*}$, indicating a high tone associated with the stressed syllable. This $\mathrm{H}^{*}$ analysis was applied both to prenuclear accents, whose F0 peaks were realized after the stressed syllable, and to nuclear accents, whose F0 peaks were realized within the stressed syllable. Thus what Sp_ToBI analyzes with distinct labels (i.e. $\mathrm{L}^{*}+\mathrm{H}$ and $\mathrm{L}+\mathrm{H}^{*}$ ), and has been argued by Sosa and Face to be two distinct phonological accents, was viewed by Prieto and her colleagues as one pitch accent (i.e. $\mathrm{H}^{*}$ ) with different phonetic realizations. This $\mathrm{H}^{*}$ analysis has been maintained in some later work as well, such as that of Nibert (2000) on Peninsular Spanish.

Beginning with the work of Sosa $(1995,1999)$ and later Face (2001c, 2002a, 2002b, 2003), the rising accents in Spanish have generally been analyzed as bitonal $\mathrm{L}+\mathrm{H}$ accents of some sort. The motivation for the bitonal $\mathrm{L}+\mathrm{H}$ analysis is that there is an $\mathrm{F} 0$ valley that occurs at or at least very near the stressed syllable. If there were two $\mathrm{H}^{*}$ accents in sequence, one might expect some "sag" in the F0 contour between the $\mathrm{H}$ targets, but a clear F0 valley aligned consistently near the onset of the stressed syllable as in Prieto's Mexican data and in the data on Caracas and Castilian Spanish by Sosa and Face, respectively, would not be expected and would have no explanation. ${ }^{7}$

\footnotetext{
${ }^{7}$ Prieto (1998), however, does recognize that presence of an F0 valley, but argues against it being the result of a phonological $\mathrm{L}$ tone.
} 
Further, even if the F0 valley were to be attributed to sag between $\mathrm{H}$ targets, this could not explain why the first accent of an utterance, where there is no preceding $\mathrm{H}^{*}$ to sag from, would have an F0 valley aligned near the onset of the stressed syllable.

In spite of the widespread use of the $\mathrm{L}^{*}+\mathrm{H}$ and $\mathrm{L}+\mathrm{H}^{*}$ labels in Spanish as described above, recently some authors have pointed out problems with this 'standard' analysis and the way of assigning a star to one tone of the bitonal pitch accent (e.g. Arvaniti, Ladd \& Mennen, 1998; Ladd, Faulkner, Faulkner \& Schepman, 1999; Atterer \& Ladd, 2004). Face (2001b) proposed for Castilian Spanish that $\mathrm{L}^{*}+\mathrm{H}$ be used as described above, but that the accent with the F0 peak on the tonic syllable be analyzed as $(\mathrm{L}+\mathrm{H})^{*}$. This parenthetical notation was proposed due to the fact that the difference in tonal alignment affects the F0 peak, but not the F0 valley. That is, in the $\mathrm{L}^{*}+\mathrm{H}$ pitch accent the F0 valley is aligned near the onset of the stressed syllable and the F0 peak generally occurs in a post-tonic syllable. In what has typically been analyzed as a $\mathrm{L}+\mathrm{H}^{*}$ pitch accent, the F0 peak is aligned with the stressed syllable (hence the star on the $\mathrm{H}$ tone), but the $\mathrm{L}$ is no less aligned than it is in the $\mathrm{L}^{*}+\mathrm{H}$ accent. Therefore, Face (2001b) argues, both tones are aligned with the stressed syllable and $(\mathrm{L}+\mathrm{H})^{*}$ more accurately reflects the tonal alignment facts than does $\mathrm{L}+\mathrm{H}^{*}$. Recognizing the same problem in her analysis of Peruvian Spanish, O'Rourke (2005) uses a notational variant to the parenthetical notation to indicate the alignment of both tones of the pitch accent. Instead of the $\mathrm{L}^{*}+\mathrm{H}$ vs. $(\mathrm{L}+\mathrm{H})^{*}$ analysis proposed by Face $(2001 \mathrm{~b})$, O'Rourke proposes a $\mathrm{L}^{*} \mathrm{H}$ vs. $\mathrm{L}^{*} \mathrm{H}^{*}$ distinction, with the star on each tone of the $\mathrm{L}^{*} \mathrm{H}^{*}$ accent representing the alignment of both tones to the stressed syllable. ${ }^{8}$

The $(\mathrm{L}+\mathrm{H}) *$ notation has been used in ways other than that proposed by Face (2001b). Hualde (2002) employs the $(\mathrm{L}+\mathrm{H})^{*}$ notation in place of both $\mathrm{L}^{*}+\mathrm{H}$ and $\mathrm{L}+\mathrm{H}^{*}$. Hualde (2002) agrees that $\mathrm{H}^{*}$ is not a satisfactory analysis of rising pitch accents in Spanish, since the consistently aligned F0 valley seems to require a $\mathrm{L}$ preceding the $\mathrm{H}$, and thus a $\mathrm{L}+\mathrm{H}$ analysis of some sort. However, his $(\mathrm{L}+\mathrm{H})^{*}$ analysis maintains a different aspect of the original $\mathrm{H}^{*}$ analysis: it considers the two F0 patterns typically analyzed as $\mathrm{L}^{*}+\mathrm{H}$ and $\mathrm{L}+\mathrm{H}^{*}$ to be phonetic realizations of the same pitch accent (i.e. they are allophonic). Hualde proposes that the two tones have essentially an equal relationship to the stressed syllable, and therefore chooses the $(\mathrm{L}+\mathrm{H})^{*}$ representation to indicate the association of both tones with the stressed syllable.

Elordieta \& Calleja (2005) propose avoiding the specification of one tone as stronger than the other in a different way. They propose that the star notation be eliminated altogether. Given the differences that they find in peak alignment between Vitoria Spanish and Lekeitio Spanish, they suggest that

\footnotetext{
${ }^{8}$ O'Rourke does not use + to link the two tones of the pitch accent. The reader is
} referred to her explanation of this decision (O'Rourke, 2005:105). 
these dialects implement one phonological pitch accent in different ways. They suggest that we "view phonetic alignment of accentual tones... as the surface manifestation of a set of instructions that are part of the phonetic grammar...Thus, the pitch accents in V[itoria] S[panish] and the ones proposed earlier for L[ekeitio] S[panish] and M[adrid] S[panish] could be reinterpreted as a continuum of $\mathrm{L}+\mathrm{H}$ accents with different phonetic specifications for tonal alignment." (Elordieta \& Calleja, 2005:434-435). By claiming that the phonological unit is a $\mathrm{L}+\mathrm{H}$ pitch accent with tones specified, but no tone signalled as stronger than the other through the star notation, Elordieta \& Calleja rely on differences in phonetic implementation to explain differences in tonal alignment across varieties of Spanish. This analysis is adequate for the cases they consider, but would not be able to account for contrastive tonal alignment between rising accents within a single variety of Spanish.

What can be seen from this discussion is that while $\mathrm{L}^{*}+\mathrm{H}$ and $\mathrm{L}+\mathrm{H}^{*}$ are commonly used to describe the rising F0 patterns described above for Spanish, these are not the only analyses, and certainly there are issues to consider in any analysis (such as whether or not the two rising patterns merit analysis as two distinct phonological units rather than phonetic variants of a single phonological unit). But the issue becomes even more complicated when another type of rising F0 pattern is considered, as will be seen in the following section.

\subsection{A third Spanish rising accent}

While most reported differences in the shape of rising accents in Spanish involve primarily a difference in the alignment of the F0 peak, Willis (2003) found a different type of distinction between rising accents in Dominican Spanish that involves where the rise begins (i.e. where the $\mathrm{L}$ is realized). $\mathrm{He}$ finds one accent, used for narrow focus, with an F0 valley aligned near the onset of the stressed syllable (i.e. an early rise) and an F0 peak in a post-tonic syllable, having the shape of the prenuclear accent found in many varieties of Spanish. The other accent, used as a broad focus prenuclear accent in Dominican Spanish, is differentiated from the narrow focus accent not in the alignment of the F0 peak, but rather in where the rise begins. In this accent there is a low F0 throughout much of the stressed syllable, and then a rise in F0 beginning near the end of the stressed syllable (i.e. a late rise) and occurring primarily in a post-tonic syllable. ${ }^{9}$ It is clear that there is a

\footnotetext{
${ }^{9}$ While it is unclear whether the contrast found by Willis (2003) for Dominican Spanish between the early rise and late rise accents, both with late peaks, occurs in other Caribbean varieties of Spanish, the late rise seems to be common in at least the Spanish of Caracas, Venezuela. In addition to the example on the Sp_ToBI website mentioned above, figures in Sosa (1999) show many cases of late rises in prenuclear position (which he analyzes as $\mathrm{L}^{*}+\mathrm{H}$ ). For example, late rises can be
} 
phonological contrast between these two Dominican pitch accents. A schematic representation of these pitch accents is seen in Figure 2.

early rise

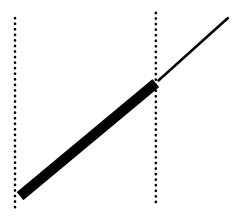

late rise

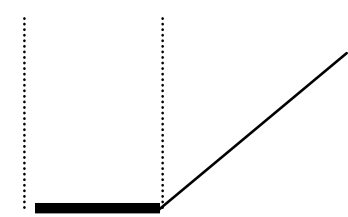

Figure 2. Schematic representations of the Dominican Spanish early rise and late rise pitch accents as described by Willis (2003).

This contrast poses a challenge to the notational system of the AM model, as here we have two contrastive rising pitch accents, but in both cases the F0 valley is aligned with the stressed syllable (though in different ways) and the F0 peak is not aligned with the stressed syllable in either accent. Based on tonal alignment, $\mathrm{L}+\mathrm{H}^{*}$ does not seem to be an adequate analysis for either accent, leaving only $\mathrm{L}^{*}+\mathrm{H}$ within the standard AM analysis. While $\mathrm{L}^{*}+\mathrm{H}$ has been used in Sp_ToBI and several other analyses of Spanish rising accents as the analysis for a rise where the F0 valley is aligned near the onset of the stressed syllable, the other Dominican rising pitch accent has a low F0 clearly aligned within the stressed syllable. In fact, this Dominican accent with the late rise seems to have the $\mathrm{L}$ more centrally associated with the stressed syllable since the low F0 occupies the majority of the stressed syllable. Therefore Willis (2003) analyzes the Dominican prenuclear accent, with the low F0 throughout the stressed syllable and the rise that begins near the end of the stressed syllable, as $\mathrm{L}^{*}+\mathrm{H}$.

Since there is a clear contrast between the two pitch accents in Dominican Spanish, another analysis is needed for the focal accent where the rise begins near the onset of the stressed syllable. Being that he has already used $\mathrm{L}^{*}+\mathrm{H}$ for the late-rise accent, and being that $\mathrm{L}+\mathrm{H}^{*}$ is not adequate based on tonal alignment, Willis analyzes the early-rising accent as $(\mathrm{L}+\mathrm{H})^{*}$. This use of the parenthetical notation is different from both uses mentioned in the previous section. However, while Willis does not follow Hualde in analyzing all F0 rises as $(\mathrm{L}+\mathrm{H})^{*}$, he does follow Hualde in using the $(\mathrm{L}+\mathrm{H})^{*}$ notation to indicate that neither tone is more centrally related to the stressed syllable than the other.

found on pages 120 and 121 for declaratives, pages 122 and 146 for interrogatives, and page 128 for exclamatives. 
Given the goal of Sp_ToBI to be a pan-Spanish ToBI system, it is quite problematic that $\mathrm{L}^{*}+\mathrm{H}$ has been used for two different F0 patterns in Spanish, and that the exact same F0 pattern (i.e. the rise with the F0 valley aligned near the onset of the stressed syllable and the F0 peak in a post-tonic syllable) has received multiple analyses. ${ }^{10}$ Two of the factors that are clearly involved in creating these difficulties of analysis are different views of starredness within the AM model and the inability of the standard AM model to account for more than a two-way contrast in rising (i.e. $\mathrm{L}+\mathrm{H}$ ) accents. The issue of starredness is addressed in the next section.

\subsection{Starredness in the AM model}

The star notation on one tone of a pitch accent has two related, yet distinct, functions in typical AM analyses. In Pierrehumbert's (1980) original representational analysis of American English, tones were marked with a star * to indicate their association with metrically strong syllables. In bitonal pitch accents, one tone was considered to be associated (in the autosegmental sense of association) with a metrically strong syllable (i.e. typically the stressed syllable), and this was the tone that was marked with a star.

As is well-known, pitch accent types can be phonologically distinguished by their relative alignment with the stressed syllable. Pierrehumbert (1980) showed that tonal alignment functions contrastively in English and that early aligned pitch accents are phonologically distinct from late aligned pitch accents. Pierrehumbert \& Steele's (1989) results are consistent with the idea that there is a categorical difference between the two accents. They undertook an imitation task with the two intonation patterns of the utterance Only a millionaire (underlining indicates the stressed syllable) illustrated in Figure 3. The results of the experiment revealed the existence of two separate phonological categories (see also later experiments by Ward \& Hirschberg, 1985; Hirschberg \& Ward, 1992; Arvaniti \& Gårding, in press; among others, which confirmed a clear separation between the two). The AM representations shown in Figure 3 (i.e. $\mathrm{L}^{*}+\mathrm{H}$ and $\mathrm{L}+\mathrm{H}^{*}$ ) capture the fact that the $\mathrm{L}+\mathrm{H}$ shape is aligned differently in the two contrastive pitch accents. While $\mathrm{L}^{*}+\mathrm{H}$ has a $\mathrm{L}$ on the stressed syllable and a $\mathrm{H}$ trailing it, $\mathrm{L}+\mathrm{H}^{*}$ has a $\mathrm{H}$ on the stressed syllable with a L leading it.

Many scholars working on the intonation of various languages have assumed a one-to-one relationship between the star and phonetic alignment. Pierrehumbert \& Beckman (1988:234) note that "the * diacritic marks which tone of a bitonal accent is aligned with stress". Yet other scholars present

${ }^{10}$ One might question whether Sp_ToBI should attempt to provide a pan-Spanish transcription system, as do the anonymous reviewers and one of the authors, since in other areas of phonology the same phonological unit (e.g. phoneme) has different realizations across language varieties and across languages. In attempting a partial revision of $\mathrm{Sp}$ _ToBI, however, we maintain this aspect of the original proposal. 
cases where there is not a direct relationship between phonological association (indicated by the star) and phonetic alignment, including in the ToBI labeling conventions for English (Beckman \& Hirschberg, 1994; see also Beckman, Hirschberg \& Shattuck-Hufnagel, 2005). Arvaniti, Ladd \& Mennen (2000) demonstrate extensively that the use of the star diacritic to mark alignment is inadequate. Nonetheless, in work on a wide variety of languages, and as can be clearly seen for Spanish in the preceding sections, one of the most common interpretations of the star notation is that the starred tone is to be phonetically aligned with the stressed syllable. The relationship between association and alignment is not always clear in the literature, and contradictory claims have been made.
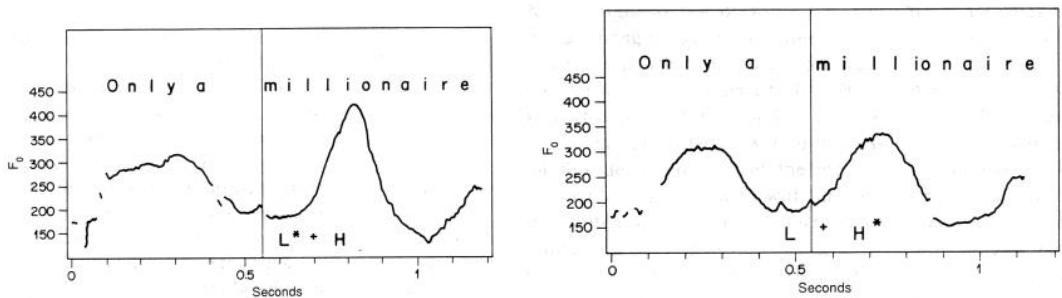

Figure 3. Fundamental frequency contour of the utterance Only a millionaire spoken with two different pitch accents on millionaire: the late-aligned pitch accent, which indicates incredulity or uncertainty (right panel), and the early-aligned pitch pattern, which indicates assertion (left panel). The vertical cursor is placed at the $[\mathrm{m}]$ release in millionaire. [figures taken from Pierrehumbert \& Steele, 1989:182].

In the case of the Spanish rising accents under consideration here, there are clear mismatches between the proposed phonological association and phonetic alignment. The accents described by Sp_ToBI as $\mathrm{L}^{*}+\mathrm{H}$ and $\mathrm{L}+\mathrm{H}^{*}$ can show identical alignment of the $\mathrm{L}$, even though in one case the $\mathrm{L}$ bears a star and in the other case it does not. Furthermore, the $\mathrm{L}^{*}+\mathrm{H}$ label is used to refer to rises with late peaks regardless of the alignment of the $\mathrm{L}$, yet Willis (2003) demonstrates that there is a phonological contrast between accents with late peaks based on the alignment of the L. If, instead of indicating alignment, the $*$ is meant to indicate the metrically stronger tone of the two tones in a bitonal pitch accent, a different problem arises with the Sp_ToBI analysis of Spanish. In the case of the standard analyses of $\mathrm{L}^{*}+\mathrm{H}$ and $\mathrm{L}+\mathrm{H}^{*}$ in declaratives in many varieties of Spanish, this viewpoint would indicate that in $\mathrm{L}^{*}+\mathrm{H}$ the $\mathrm{L}$ is the strong tone while in $\mathrm{L}+\mathrm{H}^{*}$ the $\mathrm{H}$ is the strong tone. Yet when speakers of Castilian Spanish hear these accents, they perceive both of them as primarily high. ${ }^{11}$ This corresponds to what Prieto, D'Imperio \& Gili-

11 An experimental study is needed to confirm this impressionistic perception as general among speakers of Castilian Spanish. Nonetheless, J. I. Hualde (personal communication) points out that the perceptual procedure employed here of assigning a star to either $\mathrm{L}$ or $\mathrm{H}$ is the same procedure used by Bantu tonologists. In 
Fivela (2005:374) report when they state that "in order for a syllable to be perceived as high, the pitch level needs to stay high or rise for a good portion of the accented syllable; conversely, in order for a syllable to be perceived as low the pitch level must stay low or fall during the accented syllable." Thus, following the viewpoint that the star indicates the strong tone of the pitch accent that is associated with the stressed syllable, and given that both of the declarative pitch accents in Spanish are perceived as high, it seems that both of these accents should be analyzed as $\mathrm{L}+\mathrm{H}^{*}$. There is no way, then, to distinguish these two accents as the AM model does not allow for multiple distinct $\mathrm{L}+\mathrm{H}^{*}$ accents. In fact, Pierrehumbert \& Beckman (1988:159) state that association alone cannot account for this type of difference, and suggest that in cases where it is desirable to do so it would need to be done through language-specific rules of phonetic interpretation rather than through phonological specification.

In spite of Sp_ToBI's goal to provide a pan-Spanish transcription system, it could be argued that the $\mathrm{L}^{*}+\mathrm{H}$ vs. $\mathrm{L}+\mathrm{H}^{*}$ distinction is sufficient for any variety of Spanish with only two contrastive rising pitch accents, although these labels may represent different phonetic patterns in different varieties. However, as we show in Section 3, Castilian Spanish not only has the two rising accents typically analyzed as $\mathrm{L}^{*}+\mathrm{H}$ and $\mathrm{L}+\mathrm{H}^{*}$, but also has a third rising accent similar to the Dominican Spanish late-rising accent. This threeway contrast in rising accents poses a problem for the AM model, and therefore for the Sp_ToBI system, which can only represent a two-way contrast through standard uses of the star notation and cannot accommodate a three-way contrast in rising (or falling) accents in its present state. While a diacritic or other arbitrary notational mechanism could be proposed to account for a three-way contrast, we offer in Section 4 a principled analysis that not only accounts for the three-way contrast, but also explains why such a contrast should exist, while at the same time providing a more straightforward use of starredness in the AM model.

\section{Three-way contrast in Castilian Spanish rising accents}

\subsection{Broad focus and narrow focus in declaratives}

In Castilian Spanish, prenuclear broad focus accents have late F0 peaks while prenuclear narrow focus accents have earlier F0 peaks (de la Mota, 1995, 1997; Nibert, 2000; Face, 2001b, 2001c, 2002a; Hualde, 2002, 2003a). ${ }^{12}$ Examples of the broad focus late peak and the narrow focus early

this tradition, each syllable is labeled either $\mathrm{H}$ or $\mathrm{L}$ depending on the perception of the syllable as high or low. Yet, at the surface level, $\mathrm{H}$ will be either realized as a rising tone or a high pitch plateau and $\mathrm{L}$ as a falling tone or a low pitch plateau.

12 Ladd (1980) makes a distinction between broad focus and narrow focus, where these terms relate to the size of the syntactic constituent referring to the discourse element in focus. Broad focus refers to cases where no one portion of an utterance 
peak can be seen in Figure 4, adapted from Face \& D'Imperio (2005), where the shading indicates the stressed syllable of the word terminó. While we propose that his previous analyses based on tonal alignment patterns must be revised, it is important to note that Face (2001b, 2001c, 2002a) has argued (and the position has become the 'standard', though not only, view) that there is a clear contrast between these two types of rising accents that cannot be explained as the result of phonetic influence on peak alignment. There is, then, a two-way contrast in rising accents in prenuclear position in Castilian Spanish. It must be noted that the alignment of the F0 peak is not the only intonational difference between broad focus and narrow focus utterances. Very common is a post-focal pitch reduction, sometimes with reduced F0 peaks and sometimes with no visible F0 peaks in a pitch track. The example in the right panel of Figure 4 illustrates this post-focal pitch range reduction. The F0 peak height is also sometimes, but not always, higher in narrow focus accents than in broad focus accents. So while there is indeed a contrast in the alignment of the F0 peak between broad focus and contrastive focus, there are other intonational cues to this distinction as well. In the following sections we will demonstrate that Castilian Spanish has not only these two rising accents in prenuclear position, but a third rising accent as well.

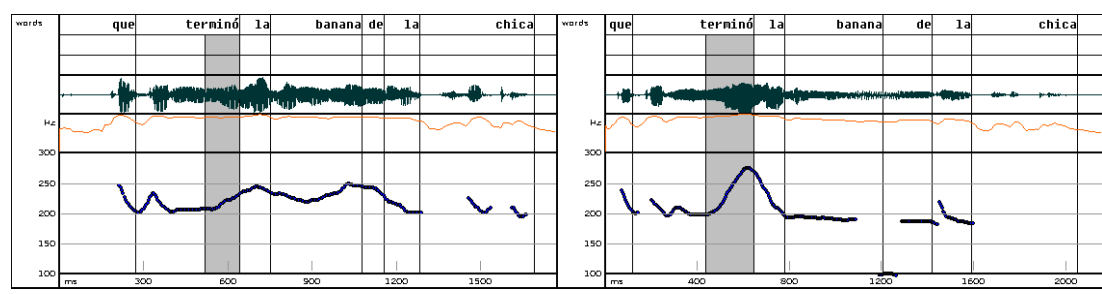

Figure 4. Broad focus reading (left panel) of the sentence Que terminó la banana de la chica 'That she finished the girl's banana', and a reading of the same sentence with narrow focus on terminó (right panel). Adapted from Face \& D'Imperio (2005).

\subsection{Focus in absolute interrogatives}

In a recent study, Face (in press) has considered the intonational marking of narrow focus in Castilian Spanish absolute interrogatives. Speakers of Castilian Spanish read a list of contextualized absolute interrogatives. ${ }^{13}$ There

is highlighted more than the others. Narrow focus, on the other hand, refers to a portion of the larger utterance, whether a complex syntactic phrase or a single lexical item, being highlighted more than the rest of the utterance.

13 The term absolute interrogative refers to the same type of questions as do the terms polar interrogatives and yes/no interrogatives. While a common term in work on Spanish intonation, as well as some other related languages, it was brought to our attention by an anonymous reviewer that absolute interrogative is not a term used by all scholars. 
were five target interrogatives, each containing three stressed words as well as unstressed words such as articles and prepositions. Each of the five target interrogatives was placed into four different contexts, where each context was a declarative sentence presenting information that preceded the interrogative. Three of the contexts forced a reading of the interrogative with narrow focus on one of the three stressed words. The fourth context for each target interrogative resulted in a reading of the interrogative in broad focus, with no portion of the interrogative highlighted over the others. The contextualizing sentence and target interrogative were presented as two-line mini-dialogues. The five speakers that participated in the study were presented these two-line dialogues in random order on sheets of paper, and these speakers then read each contextualizing sentence to themselves and then read the interrogative response out loud. Speakers were instructed to read the interrogative as they would in response to the contextualizing sentence.

Face (in press) found that the most frequent manner in which speakers of Castilian Spanish mark narrow focus with intonation in Castilian Spanish absolute interrogatives is through an F0 pattern similar to the late-rising accent reported by Willis (2003) in cases of broad focus in Dominican Spanish declaratives. ${ }^{14}$ In Castilian Spanish, a narrowly focused word in an absolute interrogative most often is characterized by a low F0 throughout the stressed syllable that then begins to rise near the end of the stressed syllable so that the rise is primarily in the post-tonic syllable. In some cases the F0 is still falling early in the stressed syllable or is rising by late in the stressed syllable, but the F0 is predominantly low in the stressed syllable, while in the other two rising accents in Castilian Spanish the F0 predominantly rises during the stressed syllable. Examples of this late-rising accent as markers of narrow focus in Castilian Spanish absolute interrogatives are seen in Figure 5, where the stressed syllable of the focal word is shaded.

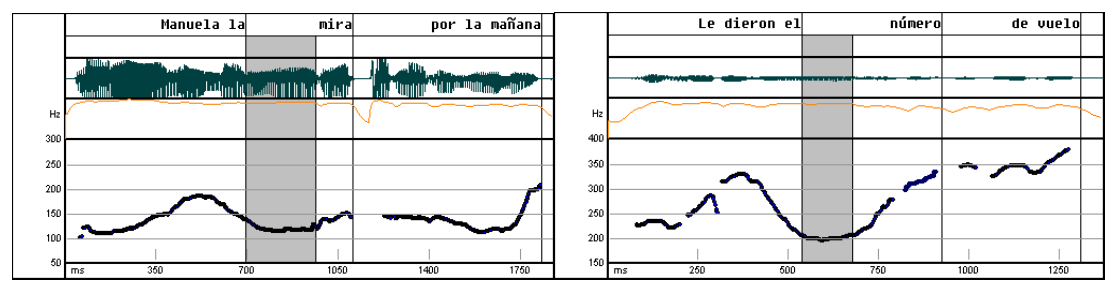

Figure 5. Late-rising accents marking narrow focus in Castilian Spanish interrogatives. The left panel has focus on the word mira in the sentence ¿Manuela la mira por la mañana? 'Does Manuela look at it in the morning?'.

The right panel has focus on the word número in the sentence ¿Le dieron el número de vuelo? 'Did they give her the flight number?'

14 The reader is referred to Face (in press) for the other intonation patterns used to mark narrow focus in Castilian Spanish absolute interrogatives, as they are irrelevant to the present study. 
The existence of a late-rising accent in prenuclear position in Castilian Spanish, when considered in conjunction with the two early-rising accents (i.e. those that begin rising near the onset of the stressed syllable, one with a late peak and one with an early peak) brings to three the number of rising accents in Castilian Spanish in prenuclear position.

\subsection{Prenuclear accents in confirmation-seeking yes-no questions}

The late-rising accent found to mark narrow focus in absolute interrogatives has other functions as well in Castilian Spanish. For example, utteranceinitial prenuclear accents in confirmation-seeking yes-no questions are typically realized as late-rising accents. The empirical basis for the examples in this section come from recordings of 8 speakers aged 19-20 from the city of Albacete (Albacete province, Castilla-LaMancha region) conducted by López Campillo (in prep) as part of her Ph.D. Project. The speakers participated in two cooperative tasks, a conventional map-task and an animal drawing task. These tasks had always the same information giver and 8 information seekers. As is well-known, the original HCRC Map Task (Anderson, Bader, Bard, Boyle, Doherty, Garrod, Isard, Kowtko, MacAllister, Miller, Sotillo, Thompson \& Weinert, 1991) involves verbal cooperation between two participants who each have a map. One of the participants has to reproduce as accurately as possible the route, which is not printed in his map, and has to ask questions to the other participant, who has a map with the target route. The task is complicated by the fact that there are a number of discrepancies between the two maps. In this setting, different types of questions are uttered by the information seeker (and also, though to a lesser extent, by the information giver).

One of the well-established distinctions in the analysis of task-oriented dialogue corpus in English and in Italian is the one between informationseeking questions, referred to as 'queries', and confirmation-seeking questions, referred to as 'checks' (e.g. Bolinger, 1989; Grice \& Savino, 2003). While in the former the speaker believes that the information being asked about is new information, confirmation-seeking questions are about information which the speaker believes he has inferred in some way. In López-Campillo's (in prep) database, confirmation-seeking questions are distinguished from information-seeking questions by means of intonation, much in the same way Grice \& Savino (2003) found for Bari Italian. The most common intonation contour used to express confirmation-seeking questions in Castilian Spanish is through an F0 pattern which starts with a late-rising accent. Examples of these F0 contours are shown in Figure 6, where the accented syllable associated with the target pitch accent is shaded. In both cases, the utterance-initial late-rising pitch accent is predominantly low throughout the stressed syllable and it only begins to rise in the post-tonic syllable. 


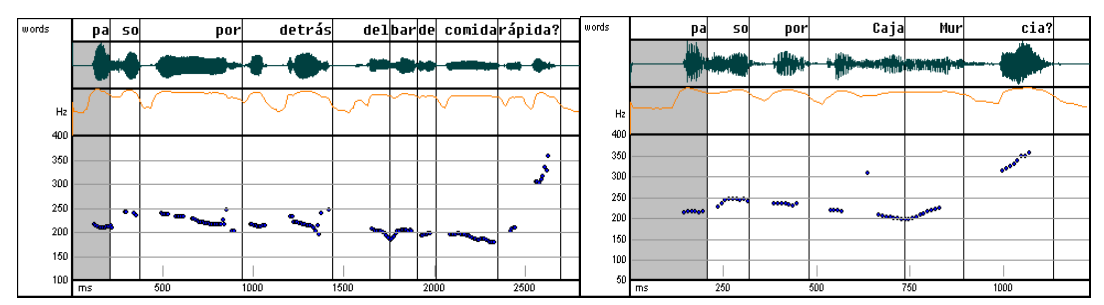

Figure 6. Late-rising prenuclear accents in Castilian Spanish confirmation-seeking questions. The left panel shows a late-rising accent on the initial word paso in the sentence ¿Paso por detrás del bar de comida rápida? 'Do I pass behind the fast-food restaurant?'. The right panel shows a late-rising accent on the word paso in the sentence ¿Paso por Caja Murcia? 'Do I go to Murcia Bank?'

As is well known, information-seeking absolute interrogatives in Castilian Spanish are intonationally characterized by an early rising accent associated with the first stressed syllable, followed by a continuously falling F0 gesture line over the phrase-medial stressed syllables. ${ }^{15}$ The last accent is always pronounced with a low tone followed with a steep final rise (Navarro Tomás, 1944, 1948; Quilis, 1993; Face, 2004; Prieto, 2004). By contrast, the first pitch accent of a confirmation-seeking question is a late rising accent. We argue that the choice of pitch accent type appears to be strongly related to the speaker's confidence that the dialogue partner will provide confirmation as to the correctness of an inference made in the question. While confirmation-seeking questions express a bias towards the expectation that confirmation will be provided, far less confidence is displayed in information-seeking questions.

\subsection{Prenuclear accents in soft requests and commands}

Navarro Tomás (1944) described an intonational contour used to express an exhortatory statement, that is, a statement which is intended to encourage or convince the interlocutor about something. In order to confirm Navarro Tomás's impressionistic description, the examples in this section were elicited using a questionnaire which consists of a list of 80 different dialogue situations which the interviewer presents to the informant. ${ }^{16}$ The situations are especially designed to trigger a given reaction or response from the speaker,

15 While this is the only pattern reported by most scholars, Face (2004) reports that some speakers in some productions do produce rising pitch accents in phrasemedial stressed syllables.

16 These recordings are part of an exploratory study meant to lay the foundations for further analysis of the intonational variation found in Madrid Spanish (Estebas-Vilaplana \& Prieto, in prep). 
and were adapted from Prieto's (2001) questionnaire for Catalan. In order to trigger exhortative utterances, such as soft requests and commands, informants were asked to imagine that one of their friends was studying hard for an exam, and that they should say something to try to convince him or her to stop studying and accompany them to the cinema. After a negative response was given, the informants were asked to say something to try convince their friend even harder. The speakers were two female speakers from Madrid.

The examples in Figure 7 show the F0 contours of two utterances, one that express a soft request in Castilian Spanish, jVéndele el libro! 'Sell the book to him!' (left panel), and one that expresses a command, „Deja el trabajo! 'Stop working!' (right panel). As is clear from the F0 contours of these utterances, the first pitch accent is a late-rising accent, that is, the pitch stays low during (much of) the accented syllable and starts rising late in the accented syllable or in the post-tonic syllable. Shading in this figure indicates stressed syllables which bear late-rising accents.

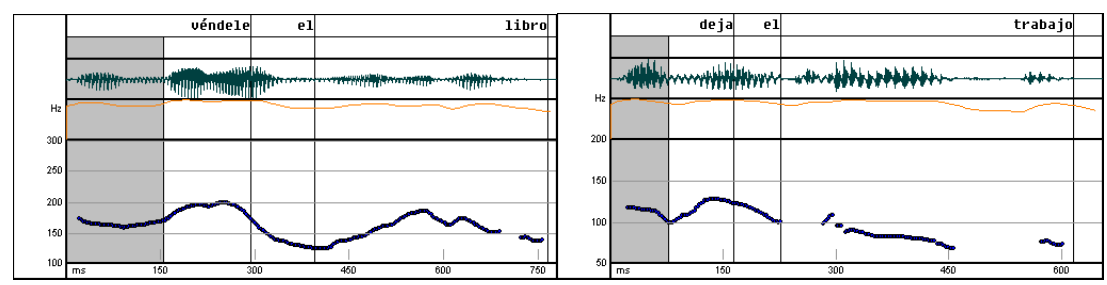

Figure 7. Late-rising prenuclear accents in Castilian Spanish a soft request (left panel) and a command (right panel). The left panel shows a late-rising prenuclear accent on the first word of the soft request Véndele el libro 'Sell the book to him!' The right panel shows a late-rising accent on the word deja in the sentence ¡Deja el trabajo! 'Stop working'.

\section{A new proposal: starredness and secondary associations}

\subsection{Starredness in the AM model: the basic contrast $L^{*}+H$ vs. $L+H^{*}$}

As mentioned earlier, the relationship between association and alignment is not always clear in the literature, and contradictory claims have been made. Based on the facts of alignment and the possibilities for phonological association of the Spanish rising accents as discussed in Section 2.4, we are in agreement with Arvaniti et al. (2000:130) when they say, based on their Greek data, that "we cannot use phonetic alignment with the stressed syllable as the defining characteristic of starred tones, that is, of their phonological association."

Following Prieto (2005) and Prieto, D’Imperio \& Gili-Fivela (2005), the use of the star diacritic will be reserved to indicate a primary phonological "association" or "affiliation" between the tone and its tone-bearing unit. The 
definition adopted here goes back to a strong version of Pierrehumbert's original proposal that "a strength relationship is defined on the two tones of bitonal accents: and that it is the stronger tone which lines up with the accented syllable" (Pierrehumbert, 1980:76-77). In bitonal accents, the star will be assigned according to perception of tone relationships. The stronger tone $(\mathrm{H}$ or $\mathrm{L})$ will be starred according to perception of the prominent syllable: that is, depending on whether the prominent syllable is heard with a "high tone" or with a "low tone" by native speakers of the language. ${ }^{17}$ It follows that the two tones in a bitonal accent are in a hierarchical relationship and that only one can be the starred tone. For more details about the four typological possibilities that arise in bitonal accents taking into account these primary associations and the procedure to obtain the F0 surface alignment pattern through a "central" mapping procedure percolating to the head, see Prieto et al. (2005:376ff). ${ }^{18}$

If the * is taken to indicate the strong tone (or the head) of the pitch accent, the two Castilian Spanish accents commonly analyzed as $\mathrm{L}^{*}+\mathrm{H}$ and $\mathrm{L}+\mathrm{H}^{*}$ should both be analyzed as $\mathrm{L}+\mathrm{H}^{*}$ since the stressed syllables bearing these accents are perceived as being high. The late-rising pitch accent with its low F0 throughout the stressed syllable seems quite clearly to merit a $\mathrm{L}^{*}+\mathrm{H}$ analysis, as the low F0 throughout the stressed syllable leads syllables bearing this accent to be perceived as low. When the * is used in this way, the laterising accent is quite easily incorporated into the analysis as $\mathrm{L}^{*}+\mathrm{H}$ as it is the only one of the three rising pitch accents in Castilian Spanish where the $\mathrm{L}$ is the strong tone of the accent. However, the broad focus declarative accent (analyzed as $\mathrm{L}^{*}+\mathrm{H}$ by $\mathrm{Sp} \_\mathrm{ToBI}$ ) and the narrow focus declarative accent (analyzed as $\mathrm{L}+\mathrm{H}^{*}$ by $\mathrm{Sp} \_\mathrm{ToBI}$ ) both seem to merit a $\mathrm{L}+\mathrm{H}^{*}$ analysis as they are both perceived as high. Given that these are clearly two distinct accents, occurring in the same prenuclear position but communicating different

17 As Pauline Welby points out, the relationship between strength and starredness is likely language- or language-class specific. Ladd (1996:59) points out that "In some languages (like English or Dutch), the metrically prominent syllables to which pitch accents are associated are also stressed. In other languages (like French or Indonesian) pitch accents may associate to syllables which are not necessarily stressed and which may not seem 'prominent' either to native speakers or to phonetically trained listeners." Similarly, Vaissière (1997:56) states that "Maints phonéticiens ont noté la difficulté particulière qu'ont les français à percevoir de façon cohérente des proéminences dans leur langue maternelle", 'Many a phonetician has noted the particular difficulty that the French have in perceiving in a coherent way prominences in their mother tongue' (translated by Pauline Welby).

18 Fernández Planas, Martínez Celdrán, Salcioli Guidi, Toledo \& Castellví (2002) also find variation in the location of prenuclear peaks in read speech in Barcelona and Alicante Spanish. They point out that the majority of peaks in oxytonic words are aligned with the stressed syllables, while this is not the case in paroxytonic and proparoxytonic words. For a thorough revision of the effects of within-word position on F0 peak location in Spanish, see Estebas-Vilaplana \& Prieto (2005) and Prieto, Estebas-Vilaplana \& Vanrell (2006). 
meanings, an analysis must distinguish them phonologically and not analyze them both as identical $\mathrm{L}+\mathrm{H}^{*}$ pitch accents.

\subsection{Secondary associations in the AM model: three-way contrasts in rising} accents in Castilian Spanish

The three diagrams in Figure 8 summarize the three-way contrast found in rising prenuclear pitch accents in Castilian Spanish: (a) early-rising pitch accents with delayed peaks, (b) early-rising pitch accents with nondelayed peak, and (c) late-rising pitch accents.
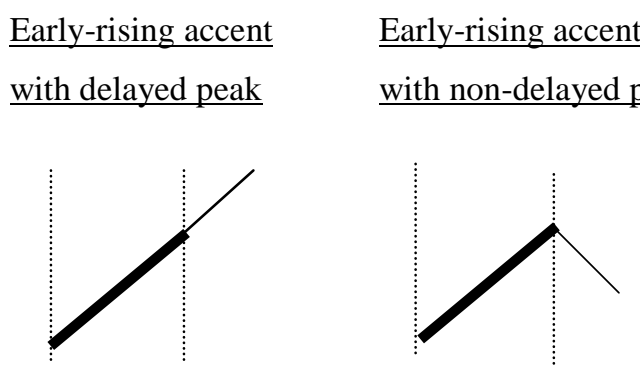

\section{$\underline{\text { Late-rising accent }}$}

\section{with delayed peak}

\section{with non-delayed peak}

Figure 8. Schematic representation of the three-way contrast in alignment in rising LH pitch accents in Castilian Spanish.

Prieto et al. (2005) have proposed that the AM theory can account for an identical three-way contrast in rising accents found in Catalan by incorporating secondary associations of tones into the theory. Secondary associations of edge tones (i.e. phrase accents and boundary tones) were originally a part of Pierrehumbert and Beckman's (1988) analysis of the Japanese intonational system and have later been proposed for a number of other languages. According to this study, edge tones are linked phonologically to the edge of a metrical phrase (e.g. intermediate phrase, intonation phrase), but may also acquire additional links (or "secondary associations") to a specific site in the metrical tree. An AM representation of a secondary association of an edge tone is shown in Figure 9, based on Pierrehumbert and Beckman's (1988) analysis of Japanese. The H phrase accent has a primary association to the edge of the accentual phrase and a secondary association to the second mora. 


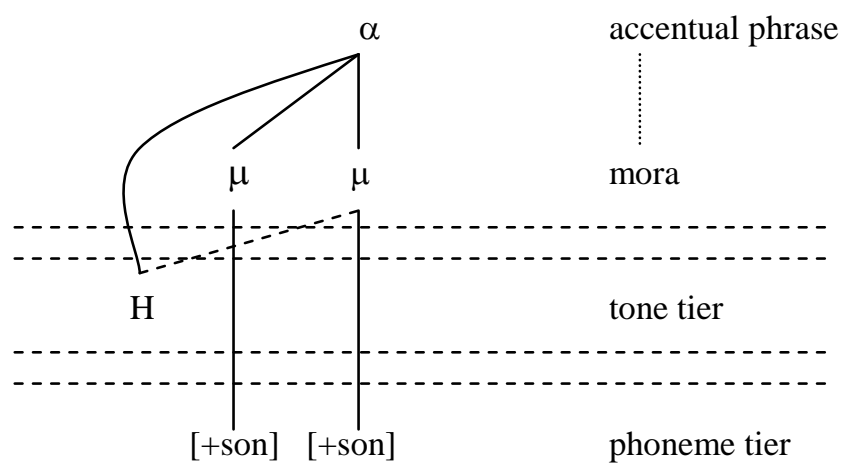

Figure 9. AM representation of the primary association of the $\mathrm{H}$ phrasal tone to the accentual phrase $\alpha$ and of the secondary association of this $\mathrm{H}$ tone to the second mora $\mu$ in Japanese (after Pierrehumbert \& Beckman, 1988, p. 129).

The concept of secondary association is thus understood as the simultaneous association of a tone to a higher-level constituent, like the intonation phrase, and a lower constituent, like the mora. This concept has gained a broad acceptance and has recently been applied to different languages to explain the behavior of phrase accents and edge tones. Edge tones have been proposed to have secondary associations to stressed syllables, moras, and word and syllable edges (see Grice, 1995:185, for Palermo Italian; Elordieta, 1998, for Lekeitio Basque; Gussenhoven \& van der Vliet, 1999, and Gussenhoven, 2000, for tonal dialects of Dutch; Grice, Ladd \& Arvaniti, 2000, for Eastern European languages; Bruce, 2003, for West Swedish; Jun \& Fougeron, 2000, and Welby, 2003, for French; Frota, 2003, for phrasal H tones in European Portuguese; and Hualde, 2003b, for Occitan). All these studies acknowledge that phrasal tones may acquire additional links ("secondary associations") to a specific site in the metrical tree. For a summary of the types of edge-tone secondary attachments that have been found in the literature, see Prieto et al. (2005:377ff).

Prieto et al. (2005) proposed that secondary associations may occur not only for edge tones, but also for pitch accents. The strong tone of the pitch accent is associated with the stressed syllable (perhaps indirectly through a foot), but as has already been mentioned, this association does not necessarily indicate a specific phonetic alignment of the tone to the stressed syllable. In fact, we have claimed here that the broad focus and narrow focus declarative pitch accents must both be analyzed as $\mathrm{L}+\mathrm{H}^{*}$, yet the alignment of the $\mathrm{H}$ is contrastive in these two cases, occurring in a post-tonic syllable in the case of the broad focus pitch accent and at the right edge of the stressed syllable in the case of the narrow focus pitch accent. Prieto et al. (2005) propose that some strong tones have a secondary association as well as their primary association, 
and that "these secondary associations will play a primary role in determining the phonetic timing of tones by overriding the standard mapping procedure applied to pitch accents with only primary associations of tones" (p. 379). This is identical to the way that a secondary association of an edge tone may result in the phonetic realization of the edge tone occurring other than at the edge of the metrical phrase, but rather at a specific mora, syllable, or word edge.

Adapting the analysis of Prieto et al. (2005) to Spanish, we can say that there is only one $\mathrm{L}^{*}+\mathrm{H}$ accent known at this point, and that there is no evidence for a secondary association of the $\mathrm{L}$ in this pitch accent since there is no contrast among $\mathrm{L}^{*}+\mathrm{H}$ accents. With respect to the two $\mathrm{L}+\mathrm{H}^{*}$ accents, we propose that a secondary association of the $\mathrm{H}$ of one of these accents distinguishes them. The narrow focus declarative accent has an F0 peak that is aligned with the stressed syllable, and we propose that this accent has a secondary association of the $\mathrm{H}$ to the stressed syllable. The broad focus declarative accent, on the other hand, has an F0 peak realized in a post-tonic syllable, and does not seem to be aligned with any particular metrical unit. Therefore the $\mathrm{H}$ appears to have only a primary association. The difference between the two $\mathrm{L}+\mathrm{H}^{*}$ accents, then, is that the broad focus declarative accent has only a primary association (i.e. $\mathrm{L}+\mathrm{H}^{*}$ ), leaving phonetic alignment of the $\mathrm{H}$ unspecified phonologically, while the narrow focus declarative accent has both a primary association and a secondary association to the stressed syllable (i.e. $\left.\mathrm{L}+\mathrm{H}^{*}\right] \sigma$ ), with the secondary association being responsible for the alignment of the $\mathrm{H}$ within the stressed syllable. ${ }^{19}$ The AM representation of the three rising pitch accents in Castilian Spanish is given in Figure 10, following Prieto et al.'s (2005) representation for Catalan.

The tonal representations proposed crucially capture the similarities between the two rising pitch accents with $\mathrm{H}^{*}$ (namely, both of them have the same $\mathrm{L}+\mathrm{H}$ accent shape and they are perceived as high) and their main differences (namely, their different anchoring points). Moreover, this type of representation enables us to characterize in a more principled way the distinction between obligatory alignment at an edge (non-delayed peaks are aligned to the right edge of the syllable) and more freely aligned targets (delayed peaks). While we have shown that a three-way contrast in rising accents exists in Castilian Spanish, some might question the applicability of this analysis to Spanish on a broader scale, as in the Sp_ToBI system. While some varieties of Spanish, such as that considered in this study, clearly have a contrast between a rising accent with a late peak and rising accent with an

19 An anonymous reviewer points out that in the $\left.\mathrm{L}+\mathrm{H}^{*}\right] \sigma$ accent the primary and secondary associations are both with the stressed syllable. While this is true, the two associations express different things. While the primary association expresses the fact that the whole accent is linked (via its strong tone or head) with the stressed syllable, the secondary association specifically links that tone to a given point in the metrical structure, specifying its alignment; that is, it allows for different types of links to take place and be relevant phonologically. 
early peak (i.e., the two $\mathrm{L}+\mathrm{H}^{*}$ accents in our analysis), other varieties do not show this contrast or show variation in peak alignment (e.g. McGory \& Díaz-Campos, 2002; Elordieta \& Calleja, 2005; O’Rourke, 2005). Nonetheless, it is important that a transcription system be able to account for this contrast. If Sp_ToBI attempts to be a pan-Spanish transcription system, as indicated by Beckman et al. (2002), then clearly it must be able to account for the Castilian Spanish contrast. The use of secondary associations provides a means through which it can do so.

$\underline{\text { Late-rising accent }}$<smiles>[Y][Y]([H])[IH+]</smiles>

[ma 'ri a] $\omega$

\section{Early-rising accent} with late peak

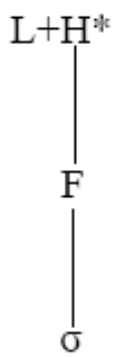

$\sigma$
Early-rising accent with early peak

Figure 10. AM representation of the primary associations (solid line) and the secondary association (dashed lines) of the individual tone $\mathrm{H}$ to the right-edge of the syllable in rising $\mathrm{L}+\mathrm{H}$ pitch accents in Castilian Spanish $(\omega=$ prosodic word, $\mathrm{F}=$ foot, $\sigma=$ syllable) [after Prieto et al., 2005:381].

\subsection{Alternatives to secondary association}

There are at least two alternatives to secondary association that could be considered. The first of these is to treat the difference in peak alignment between the two early rising accents as the result of phonetic variation. In fact, Elordieta \& Calleja (2005) consider this possibility. They state, for example, that "pitch accents in V[itoria] S[panish] and the ones proposed earlier for L[ekeitio] S[panish] and M[adrid] S[panish] could be reinterpreted as a continuum of $\mathrm{L}+\mathrm{H}$ accents with different phonetic specifications for tonal alignment" (Elordieta \& Calleja, 2005:434-435). While such a proposal makes sense in the context that they consider (i.e. alignment differences across varieties of Spanish), we believe for two reasons that this analysis cannot be maintained as a general proposal within Sp_ToBI. First, speakers do perceive the two early rising accents discussed (one with peak delay and the other without peak delay) as primarily high, indicating that the high tone is stronger than the low tone perceptually. This could not be accounted for by an analysis 
that treats rising accents simply as $\mathrm{L}+\mathrm{H}$ with alignment resulting from phonetic implementation. And if the accent is analyzed as $\mathrm{L}+\mathrm{H}^{*}$, accounting for the perception of these accents as high, but alignment is left to phonetic implementation, a second difficulty arises. Relegating tonal alignment to phonetic implementation, rather than phonological specification, cannot account for the fact that in Castilian Spanish alignment of the rising pitch accent is contrastive, with late peaks typical of broad focus accents and early peaks typical of narrow focus accents. This contrast leads us to conclude that peak alignment is categorical, and therefore must be specified phonologically and not considered to result from phonetic implementation.

Another alternative would be to use the parentheses notation in a way similar to how it has been used in previous accounts. The late rising accent could be assigned the $\mathrm{L}^{*}+\mathrm{H}$ label, as in our analysis. The early rising accent with the late peak could be assigned the $\mathrm{L}+\mathrm{H}^{*}$ label, while the early rising accent with the early peak could be assigned the $(\mathrm{L}+\mathrm{H}) *$ label. The use of parentheses would correspond with alignment, where the F0 valley and the F0 peak are aligned with the edges of the stressed syllable. Nonetheless, there are at least two problems that we see with this alternative. The first is that it does away with the hierarchical relationship between tones. While $\mathrm{L}^{*}+\mathrm{H}$ and $\mathrm{L}+\mathrm{H}^{*}$ clearly have a head marked by the star, in the $(\mathrm{L}+\mathrm{H})^{*}$ pitch accent neither tone is marked as the head of the pitch accent. The parenthetical analysis cannot account for speakers of the language perceiving this accent as high. But if the star notation is employed to indicate alignment, the parenthetical notation works well, since both tones are aligned to syllable edges. But if the star indicates alignment, there is a problem with $\mathrm{L}+\mathrm{H}^{*}$ for the early rising accent with the late peak, since it is the F0 valley, and not the F0 peak, that is aligned with the stressed syllable. The second problem that we see with this analysis is that it attempts to be purely descriptive. That is, the parenthetical notation is able to represent that both tones align with the stressed syllable, but it offers no explanation for why this should be. It is merely an arbitrary diacritic with no explanatory power. In contrast, our analysis of secondary associations explains why alignment functions in the way that it does, and even makes predictions about the locations where alignment should be expected (edges of units such as the syllable, word, etc.).

\section{Conclusion}

In this paper we have shown that Castilian Spanish has a three-way contrast in rising pitch accents. Two of these accents have rises that begin near the onset of the stressed syllable, and what differentiates them is the alignment of the peak. In one case the peak is realized in a post-tonic syllable while in the other case the peak is realized within the stressed syllable. The third rising pitch accent in Castilian Spanish can be characterized as a posttonic rise in that there is a predominantly low F0 throughout the stressed 
syllable followed by a rise in the post-tonic syllable. While there has been much recent work on rising accents in several varieties of Spanish that shows that there is considerable intra and interdialectal variation in peak alignment, we have shown here that the three rising accents in Castilian Spanish are phonologically contrastive, with each occurring in prenuclear position but communicating different meanings. This three-way contrast in rising pitch accents highlights the need to rethink the Sp_ToBI distinction (and, more generally, the standard AM model's distinction) between $\mathrm{L}^{*}+\mathrm{H}$ and $\mathrm{L}+\mathrm{H}^{*}$ pitch accents, which can systematically represent only a two-way contrast.

\section{Original Sp_ToBI}

$\mathrm{L}^{*}+\mathrm{H}$

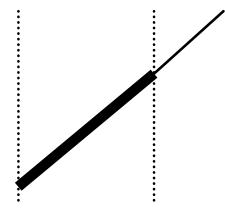

$\mathrm{L}+\mathrm{H}^{*}$
$\mathrm{L}+\mathrm{H}^{*}$

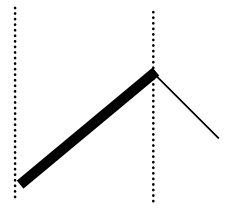

$\left.\mathrm{L}+\mathrm{H}^{*}\right] \sigma$
$\mathrm{L}^{*}+\mathrm{H}$

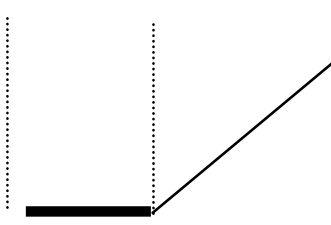

$\mathrm{L}^{*}+\mathrm{H}$

\section{Proposed Revision to Sp_ToBI}

Figure 11. Three rising pitch accents with the original Sp_ToBI analysis (Beckman et al., 2002) and our proposed revision to Sp_ToBI.

We set out to propose a partial revision of the $\mathrm{Sp}$-ToBI system, specifically in terms of its analysis of rising accents. The original Sp_ToBI system proposed by Beckman et al. (2002) included only $\mathrm{L}^{*}+\mathrm{H}$ and $\mathrm{L}+\mathrm{H}^{*}$ as rising accents, making it unable to account for a three-way contrast in rising accents such as that found in Castilian Spanish. The L*+H label was used to refer to both early and late rises with a late peak, even though we have shown here that these rises contrast in Castilian Spanish. Furthermore, Sp_ToBI distinguished early rises by the alignment of the $\mathrm{F} 0$ peak, employing $\mathrm{L}^{*}+\mathrm{H}$ for late peaks and $\mathrm{L}+\mathrm{H}^{*}$ for early peaks, even though both are perceived as high and the star does not reflect the alignment similarity between the two L tones. Considering the inadequacy of starredness to represent tonal alignment and the fact that speakers of the language perceive the early rising accents as high and the late rising accent as low, we take the star notation in the sense proposed by Pierrehumbert (1980) and advocated for by Prieto et al. (2005) to represent the strong tone (or the head) of the pitch accent. Our analysis labels late rising accents as $\mathrm{L}^{*}+\mathrm{H}$ and both early rising accents as $\mathrm{L}+\mathrm{H}^{*}$ accents, 
with the contrast in peak alignment between the $\mathrm{L}+\mathrm{H}^{*}$ accents accounted for the secondary association of the $\mathrm{H}^{*}$ tone in the accent with the early peak to the stressed syllable. Thus the accent with the late peak is analyzed as $\mathrm{L}+\mathrm{H}^{*}$, with no secondary association, while the accent with the early peak is analyzed as $\left.\mathrm{L}+\mathrm{H}^{*}\right] \sigma$, with the] $\sigma$ indicating secondary association to the stressed syllable. The result of our analysis is a proposed revision of the Sp_ToBI analysis as indicated in Figure 11.

While we believe that our analysis brings Sp_ToBI more in line with our current state of knowledge on Spanish rising pitch accents and provides a more transparent analysis of them, we also believe that the implications of this proposal go beyond the analysis of Spanish intonation. It is important to note that the Castilian Spanish data presented here are not unique in terms of the demands they place on pitch accent representation within the AM model. Prieto (2005) and Prieto et al. (2005) show that Catalan has precisely the same three rising accents that we have shown here for Castilian Spanish. Furthermore, Prieto et al. (2005) show that both the Pisa and Neapolitan varieties of Italian have contrasting tonal alignment similar to that between the two $\mathrm{L}+\mathrm{H}^{*}$ accents in Castilian Spanish. Three-way contrasts in rising accents, as well as two-way contrasts in peak alignment between accents that otherwise merit the same phonological representation, show an increasing need to specify secondary associations of pitch accent tones in the phonological representation. In our view a more complete phonological encoding of the metrical and anchoring information has advantages for the AM theoretical model. First, the specification of metrical anchoring points in the phonological representation offers a more explanatory analysis of the alignment contrasts found in Romance languages and, ultimately, can help in the task of defining a more explanatory pitch-accent typology. Finally, it makes the mapping from phonological representation to surface alignment patterns more explicit and it thus allows for more straightforward crosslinguistic comparisons.

On a cautionary note, in our proposal both the early peak and the late peak accents are regarded as sub-types of a $\mathrm{L}+\mathrm{H}^{*}$ accent, something that potentially predicts that the perceptual distinction between the two is not very strong. Even in Castilian Spanish, where these two accents do contrast, there are three facts that we can point to that may indicate that the contrast is not very strong. First, both are perceived as high accents by Castilian Spanish speakers. While rigorous perceptual experiments are needed to examine this issue further, that these two accents are both perceived as high could indicate that the difference is not very salient. Second, while a contrast is found between these two L $+\mathrm{H}^{*}$ accents in Castilian Spanish, there are recent studies on Madrid Spanish (a more narrowly defined Castilian variety) that find much more variation than has been previously reported (Prieto \& Torreira in press, Ramírez Verdugo 2005, Toledo 2006). We might expect precisely this if a contrast between two $\mathrm{L}+\mathrm{H}^{*}$ accents, with differing peak alignments, is being lost. Variation would be expected first, possibly followed by one pattern being subsumed by the other. Thirdly, in the Castilian Spanish contrast between the $\mathrm{L}+\mathrm{H}^{*}$ accents, peak alignment is not the only intonational cue to the contrast. While late peaks communicate broad focus in declaratives and early peaks communicate narrow focus, there is generally also a post-focal pitch range 
reduction present (Face, 2001a, 2001c; see right panel of Figure 4 above). It could be that this difference in pitch scaling is needed along with the peak alignment difference in order to perceive broad vs. narrow focus. Given that in Castilian Spanish, which has the contrast, there are some indications that the contrast may not be very salient perceptually, we might understand other varieties of Spanish where there is less predictable variation in peak alignment or where only one of these two alignment patterns is present as having done away with the peak alignment contrast altogether. In these varieties we would consider that only one of our two $\mathrm{L}+\mathrm{H}^{*}$ accents is part of the phonological inventory, with both present only for those varieties which maintain a contrast in peak alignment, such as the one we have shown to exist in Castilian Spanish. ${ }^{20}$

\section{Acknowledgments}

The article develops some materials and ideas presented by the two authors at the $2^{\text {nd }}$ Workshop on Spanish ToBI organized by J.I. Hualde as a Satellite Meeting to the $2^{\text {nd }}$ PaPI Conference (Barcelona, June 2005) and by the first author at the $3^{\text {rd }}$ Conference on Speech Prosody (Dresden, May 2006). We are grateful to the audience in these conferences, and especially to L. Colantoni, C. de la Mota, G. Elordieta, J.I. Hualde, M. Ortega, M. Simonet, and F. Torreira for very useful feedback. We are also indebted to G. Elordieta, P. Welby, and three anonymous reviewers for their excellent feedback on an earlier written version of this paper. Finally, we would like to thank E. Estebas and M.M. Vanrell for their help with the recordings of soft requests and commands. This research was funded by grants 2001SGR 00150, and 2001SGR 00425 from the Generalitat de Catalunya and HUM2006-01758/FILO from the Spanish Ministry of Science and Education and FEDER.

\section{References}

Anderson, A.; Bader, M.; Bard, E.G.; Boyle, E.; Doherty, G.; Garrod, S.; Isard, S.; Kowtko, J.; MacAllister, J.; Miller, J.; Sotillo, C.; Thompson, H. \& Weinert, R. (1991) The HCRC Map Task Corpus, Language and Speech, 34, 351-366.

Arvaniti, A.; Ladd, D.R. \& Mennen, I. (1998) Stability of tonal alignment: the case of Greek prenuclear accents, Journal of Phonetics, 26, 3-25.

${ }^{20}$ Even in varieties that have variation in peak placement, we would propose that they have only one $\mathrm{L}+\mathrm{H}^{*}$ pitch accent, with no secondary association of the $\mathrm{H}^{*}$ tone. Without a secondary association, the $\mathrm{H}^{*}$ tone is not specified to have any particular phonetic alignment, and may be aligned differently in different instances. That is, in these varieties early and late peaks demonstrate free variation as variant phonetic realizations of the same $\mathrm{L}+\mathrm{H}^{*}$ accent. 
Arvaniti, A. \& Baltazani, M. (2005) Greek ToBI. In Prosodic models and transcription: towards prosodic typology (S.-A. Jun, editor), pp. 84-117. Oxford: Oxford University Press.

Arvaniti, A. \& Gårding, G. (in press) Dialectal variation in the rising accents of American English. In Papers in laboratory phonology 9. Change in Phonology (J. Cole \& J. Hualde, editors). The Hague: Mouton de Gruyter.

Arvaniti, A.; Ladd, D.R. \& Mennen, I. (2000) What is a starred tone? Evidence from Greek. In Papers in laboratory phonology V: acquisition and the lexicon (M. Broe \& J. Pierrehumbert, editors), pp. 119-131. Cambridge: Cambridge University Press.

Atterer, M. \& Ladd, D.R. (2004) On the phonetics and phonology of "segmental anchoring" of F0: evidence from German, Journal of Phonetics, 32, 177-197.

Beckman, M.E. \& Ayers, G.M. (1994) Guidelines for ToBI labeling. Version 2.0. Ms. Department of Linguistics, The Ohio State University.

Beckman, M.E. \& Hirschberg, J. (1994) The ToBI annotation conventions. Manuscript. The Ohio State University. Available at: http://ling.ohio-state.edu/ $\sim$ tobi/annotation_conventions.html

Beckman, M.E.; Hirschberg, J. \& Shattuck-Hufnagel, S. (2005) The original ToBI system and the evoluation of the ToBI framework. In Prosodic typology: the phonology of intonation and phrasing (S.-A. Jun, editor), pp. 9-54. Oxford: Oxford University Press.

Beckman, M.E. \& Pierrehumbert, J.B. (1986) Intonational structure in Japanese and English, Phonology Yearbook, 3, 255-309.

Beckman, M.; Díaz-Campos, M.; McGory, J.T. \& Morgan, T.A. (2002) Intonation across Spanish, in the Tones and Break Indices framework, Probus, 14, 9-36.

Bolinger, D. (1989) Intonation and its uses. Ann Arbor: E. Arnold.

Bruce, G. (2003) Late pitch peaks in West Swedish. In Proceedings of the $15^{\text {th }}$ International Congress of Phonetic Sciences (M.J. Solé, D. Recasens \& J. Romero, editors), pp. 245-248. Barcelona: Universitat Autònoma de Barcelona.

de la Mota, C. (1995) La representación gramatical de la información nueva en el discurso. Ph.D. dissertation, Universitat Autònoma de Barcelona.

de la Mota, C. (1997) Prosody of sentences with contrastive new information in Spanish. In Intonation: theory, models and applications. Proceedings of an ESCA workshop (A. Botinis, G. Kouroupetroglou \& G. Carayiannis, editors), pp. 75-78.

Elordieta, G. (1998) Intonation in a pitch accent variety of Basque, International Journal of Basque Linguistics and Philology. ASJU, 32, 511-569.

Elordieta, G. \& Calleja, N. (2005) Microvariation in accentual alignment in Basque Spanish, Language and Speech, 48, 359-396.

Estebas-Vilaplana, E. \& Prieto, P. (2005) Production and perception of word-edge tones in Catalan and Spanish. In Proceedings of the III Congreso de Fonética Experimental, Santiago de Compostela, October 24-26, 2005.

Estebas-Vilaplana, E. \& Prieto, P. (in prep) Intonational variation in Peninsular Spanish.

Face, T.L. (2001a) Contrastive Focus and Global Intonation Patterns in Spanish, Linguistic Association of Korea Journal, 9, 1-21.

Face, T.L. (2001b) Focus and early peak alignment in Spanish intonation, Probus, 13, 223-246. 
Face, T.L. (2001c) Intonational marking of contrastive focus in Madrid Spanish. Ph.D. dissertation, The Ohio State University. Published by Lincom Europa, 2002.

Face, T.L. (2002a) Local intonational marking of Spanish contrastive focus, Probus, 14, 71-92.

Face, T.L. (2002b) Intonational marking of contrastive focus in Madrid Spanish. Munich: Lincom Europa.

Face, T.L. (2003) Un análisis fonológico del acento nuclear en el español de Madrid. In La tonía: Dimensiones fonéticas y fonológicas (E. Herrera Z. \& P. Martín Butragueño, editors), pp. 221-243. Mexico City: El Colegio de México.

Face, T.L. (2004) The intonation of absolute interrogatives in Castilian Spanish, Southwest Journal of Linguistics, 23(2), 65-79.

Face, T.L. (in press) Narrow focus intonation in Castilian Spanish absolute interrogatives, Journal of Language and Linguistics.

Face, T.L. \& D'Imperio, M. (2005) Reconsidering a focal typology: evidence from Spanish and Italian, Italian Journal of Linguistics, 17, 271-289.

Fernández Planas, A.M.; Martínez Celdrán, E.; Salcioli Guidi, V.; Toledo, G. \& Castellví Vives, J. (2002) Taxonomía autosegmental en la entonación del español peninsular. In Actas del II Congreso de Fonética Experimental, Sevilla, Universidad de Sevilla (J. Díaz García, editor), pp. 180-186. Sevilla: Laboratorio de Fonética, Facultad de Filología, Universidad de Sevilla.

Frota, S. (2003) The phonological status of initial peaks in European Portuguese, Catalan Journal of Linguistics, 2, 133 - 152.

Grice, M. (1995) The intonation of Palermo Italian: implications for intonation theory. Tübingen: Niemeyer.

Grice, M.; Ladd, D.R. \& Arvaniti, A. (2000) On the place of phrase accents in intonational phonology, Phonology, 17, 143-185

Grice, M. \& Savino, M. (2003) Map tasks in Italian: asking questions about given, accessible and new information, Catalan Journal of Linguistics, 2, 153-180.

Gussenhoven, C. (2000) The boundary tones are coming: on the nonperipheral realization of boundary tones. In Papers in laboratory phonology V: acquisition and the lexicon (M. Broe \& J. Pierrehumbert, editors), pp. 132-151. Cambridge: Cambridge University Press.

Gussenhoven, C. \& van der Vliet, P. (1999) The phonology of tone and intonation in the Dutch dialect of Venlo, Journal of Linguistics, 35, 99-135.

Hirschberg, J. \& Ward, G. (1992) The influence of pitch range, duration, amplitude and spectral features on the interpretation of the rise-fall-rise intonation contour in English, Journal of Phonetics, 20, 241-251.

Hualde, J.I. (2002) Intonation in Spanish and the other Ibero-Romance languages: overview and status quaestionis. In Romance phonology and variation. Selected papers from the $30^{\text {th }}$ Linguistic Symposium on Romance Languages (C. Wiltshire \& J. Camps, editors), pp. 101-116. Amsterdam: John Benjamins.

Hualde, J.I. (2003a) El modelo métrico y autosegmental. In Teorías de la entonación (P. Prieto, editor), pp.155-184. Barcelona: Ariel.

Hualde, J.I. (2003b) Remarks on the diachronic reconstruction of intonational patterns in Romance with special attention to Occitan as a bridge language, Catalan Journal of Linguistics, 2, 181 - 205.

Jun, S.-A. (ed.). (2005) Prosodic models and transcription: towards prosodic typology. Oxford: Oxford University Press. 
Jun, S.-A. \& Fougeron, C. (2000) A phonological model of French intonation. In Intonation: analysis, modeling and technology (A. Botinis, editor), pp. 209-242. Boston: Kluwer.

Kimura, T. (2006) Mismatch of stress and accent in spoken Spanish. In Prosody and syntax: cross-linguistic perspectives (Y. Kawaguchi, I. Fónagy \& T. Moriguchi, editors), pp. 141-155. Amsterdam: John Benjamins.

Ladd, D.R. (1980) The structure of intonational meaning. Bloomington: Indiana University Press.

Ladd, D.R. (1996) Intonational phonology. Cambridge: Cambridge University Press.

Ladd, D.R.; Faulkner, D.; Faulkner, H. \& Schepman, A. (1999) Constant "segmental anchoring" of F0 movements under changes in speech rate, Journal of the Acoustical Society of America, 106, 1543-1554.

López Campillo, R. (in prep) Map-tasks in Spanish: the intonation of interrogative utterances. Ph.D. dissertation, Universitat Autònoma de Barcelona.

McGory, J.T. \& Díaz-Campos, M. (2002) Declarative intonation patterns in multiple varieties of Spanish. In Structure, meaning, and acquisition in Spanish (J.F. Lee, K.L. Geeslin \& J.C. Clements, editors), pp. 73-92. Somerville, MA: Cascadilla.

Navarro Tomás, T. (1944) Manual de entonación española. New York: Hispanic Institute in the United States.

Navarro Tomás, T. (1948) Manual de pronunciación española, 4th edition. New York: Hafner Publishing Company.

Nibert, H.J. (2000) Phonetic and phonological evidence for intermediate phrasing in Spanish intonation. Ph.D. dissertation, University of Illinois at Urbana-Champaign.

O'Rourke, E. (2005) Intonation and language contact: a case study on two varieties of Peruvian Spanish. Ph.D. dissertation, University of Illinois at Urbana-Champaign.

Ortiz Lira, H. (1999) La aplicación de ToBI a un corpus del español de Chile, Onomazein, 4, 429-442.

Pierrehumbert, J.B. (1980) The phonology and phonetics of English intonation. Ph.D. dissertation, Massachusetts Institute of Technology.

Pierrehumbert, J. \& Beckman, M.E. (1988) Japanese tone structure. Cambridge, MA: MIT Press.

Pierrehumbert, J.B. \& Steele, S. (1989) Categories of tonal alignment in English, Phonetica, 46, 181-196.

Prieto, P. (1998) The scaling of the L tone line in Spanish downstepping contours, Journal of Phonetics, 26, 261-282.

Prieto, P. (2001) L'entonació dialectal del català: el cas de les frases interrogatives absolutes", In Actes del Novè Col.loqui d'Estudis Catalans a Nord-Amèrica (A. Bover, M.-R. Lloret \& M. Vidal-Tibbits, editors), pp. 347-377. Barcelona: Publicacions de l'Abadia de Montserrat.

Prieto, P. (2004) The search for phonological targets in the tonal space: evidence from five sentence-types in Peninsular Spanish. In Laboratory approaches to Spanish phonology (T.L. Face, editor), pp. 29-59. Berlin: Mouton de Gruyter.

Prieto, P. (2005) En torno a la asociación tonal en el modelo métrico-autosegmental. Puntos controvertidos en su aplicación al catalán, Revista Internacional de Lingüística Iberoamericana, 6(3), 9-28.

Prieto, P.; D’Imperio, M. \& Gili-Fivela, B. (2005) Pitch accent alignment in Romance: primary and secondary associations with metrical structure, Language and Speech, 48, 359-396. 
Prieto, P.; Estebas-Vilaplana, E. \& Vanrell, M.M. (2006) The role of tonal alignment and slope of the rise on word-boundary identification in Catalan and Spanish Paper presented at the $10^{\text {th }}$ Conference on Laboratory Phonology, Paris, June 29July 1, 2006.

Prieto, P.; Shih, C. \& Nibert, H. (1996) Pitch downtrend in Spanish, Journal of Phonetics, 24, 445-473.

Prieto, P.; van Santen, J. \& Hirschberg, J. (1995) Tonal alignment patterns in Spanish, Journal of Phonetics, 23, 429-451.

Prieto, P. \& Torreira, F. (in press) The segmental anchoring hypothesis revisited. Syllable structure and speech rate effects on peak timing in Spanish. Journal of Phonetics.

Quilis, A. (1993) Tratado de fonología y fonética españolas. Madrid: Gredos.

Ramírez Verdugo, M. D. (2005) Aproximación a la prosodia del habla de Madrid, Estudios de Fonética Experimental, 14, 309-326.

Sahyang, K.; Andruski, J.; Casielles, E.; Nathan, G.S. \& Work, R. (2006) Acquisition of prosody in a Spanish-English bilingual child. In Proceedings of Speech Prosody 2006 (R. Hoffmann \& H. Mixdorff, editors), pp. 859-862. Dresden: TUDpress.

Sosa, J.M. (1995) Nuclear and pre-nuclear tonal inventories and the phonology of Spanish declarative intonation. In Proceedings of the Thirteenth International Congress of Phonetic Sciences (K. Elenius \& R. Branderand, editors), pp. 646-649.

Sosa, J.M. (1999) La entonación del español. Madrid: Cátedra.

Toledo, G. (2006) Tonos estrellados: una argumentación, Estudios de Fonética Experimental, 15, 99-131.

Vaissière, J. (1997) Langues, prosodias et syntaxe, Traitement Automatique des Langues, 38, 53-82.

Velázquez, E. (2006) Semi-automatic prosodic transcription of spoken Spanish in XML. In Proceedings of Speech Prosody 2006 (R. Hoffmann \& H. Mixdorff, editors), pp. 623-626. Dresden: TUDpress.

Ward, G. \& Hirschberg, J. (1985) Implicating uncertainty. The pragmatics of fall-rise intonation, Language, 61, 747-776.

Welby, P. (2003) The slaying of Lady Mondegreen, being a study of French tonal association and alignment and their role in speech segmentation. Ph.D. dissertation, The Ohio State University.

Willis, E. (2003) The intonational system of Dominican Spanish: findings and analysis, Ph.D. dissertation, University of Illinois at Urbana-Champaign.

Timothy L. Face

University of Minnesota

facex002@umn.edu
Pilar Prieto

Institució Catalana de la Recerca i Estudis Avançats (ICREA)

Universitat Autònoma de Barcelona (UAB) 